\title{
Formalized Assessment of Written Communication of Scientific Information
}

\author{
Denyce K. Wicht \\ Associate Professor \\ Suffolk University \\ Department of Chemistry and Biochemistry \\ 20 Somerset Street \\ Boston, MA 02108 \\ dwicht@suffolk.edu
}

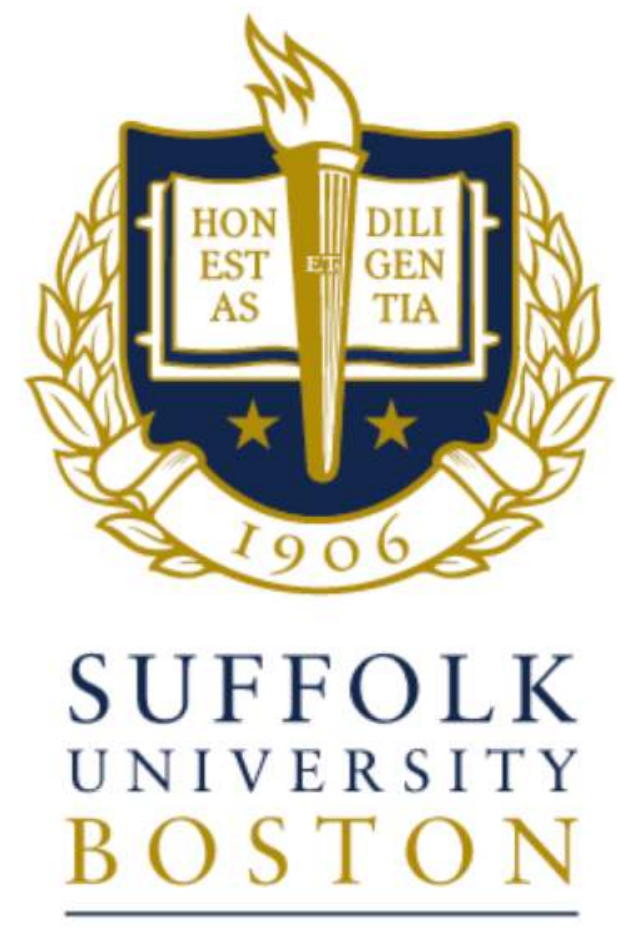

CHED SYMPOSIUM NAME: Developing \& Assessing More than Content Knowledge

March $25^{\text {th }}, 2020$ 

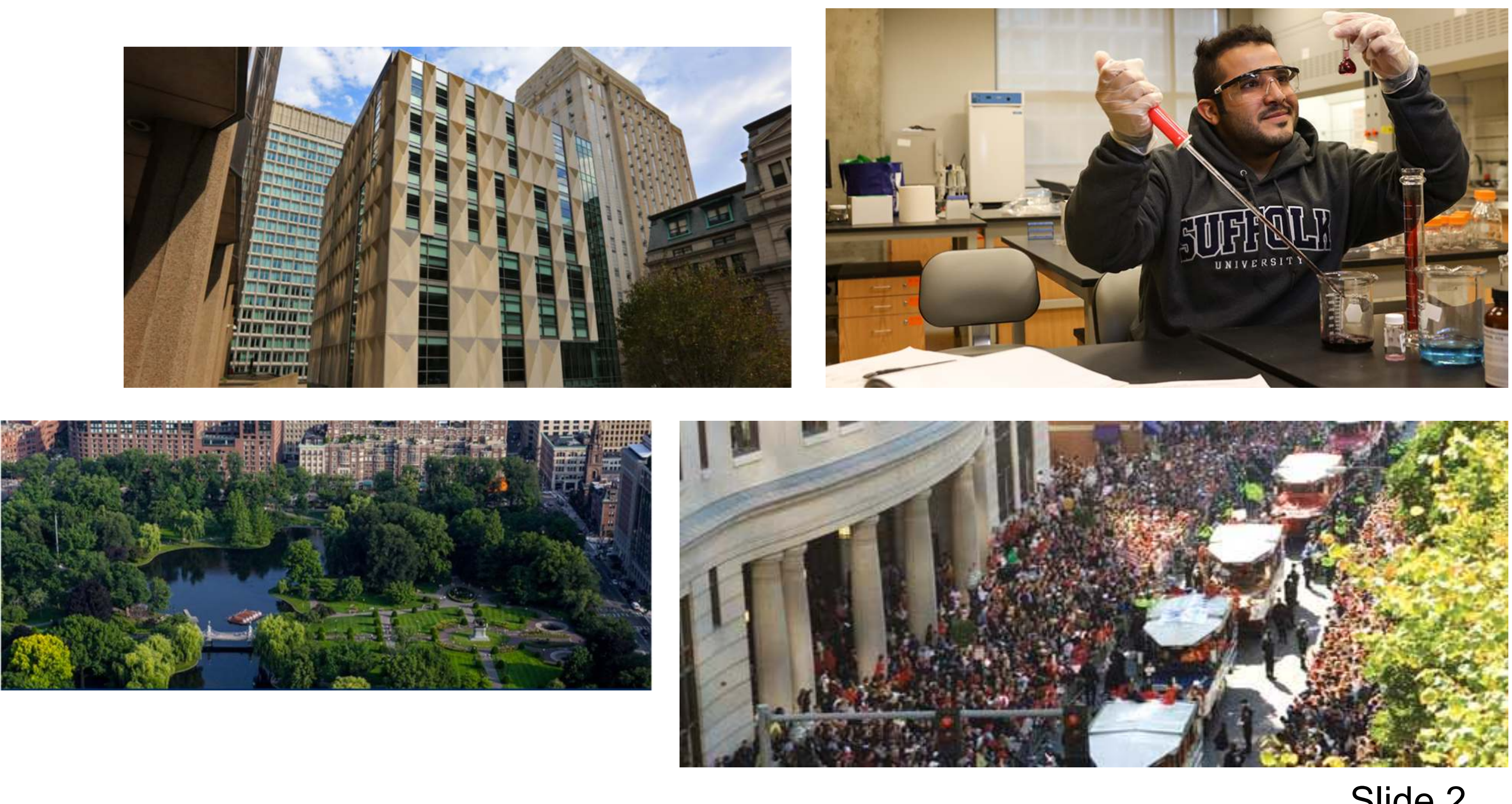

Slide 2 
Suffolk University is a private, urban university; the College of Arts and Sciences (CAS) is accredited by the New England Association of Schools and Colleges and the Department of Chemistry and Biochemistry is accredited by the American Chemical Society (ACS). Since 2013, on average, the Department graduates 10 majors per year. The Department of Chemistry and Biochemistry has four tenured or tenure-track professors and three full-time instructors.

CAS at Suffolk University is primarily an undergraduate institution; there is one graduate program in the sciences, a MS clinical program in Medical Dosimetry offered out of the Department of Biology. The teaching load for a fulltime, tenure-track faculty member in the Department of Chemistry and Biochemistry is three/two, where a laboratory course carries equal teaching weight to a lecture course. Typically, tenure-track and tenured faculty members in the Division of Physical Science (Department of Chemistry and Biochemistry and Department of Physics) teach a minimum of two laboratory courses a year. Because the Department does not support a graduate program, all research is conducted with undergraduate students.

The average overall class size is currently 20 students per faculty member. Our small class size allows faculty members to build strong relationships with students. Faculty in CAS are teacher-scholars who build important mentoring relationships with undergraduates, giving students the tools they need to transition from college to career. Nearly $50 \%$ of the undergraduate students majoring in chemistry or biochemistry at Suffolk University are hired as technicians or entry-level research assistants at local research hospitals, academic institutions, or pharma/biotech companies upon graduation. 
Research at Undergraduate Institutions: Biophysical characterization of reduced flavindependent two component monooxygenase sulfur assimilation enzymes: SfnG, MsuC, and MsuD

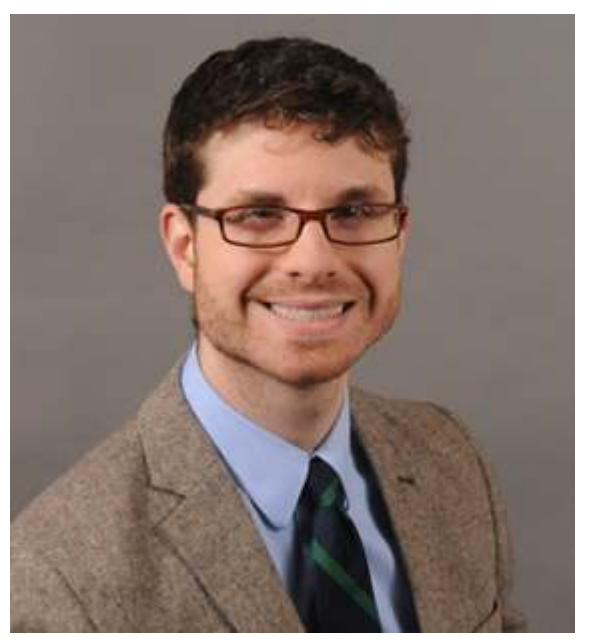

Daniel P. Dowling UMass-Boston

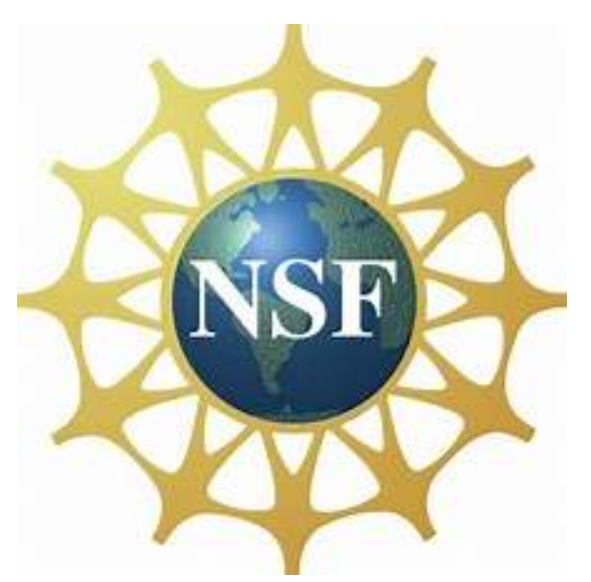

Award 1807480

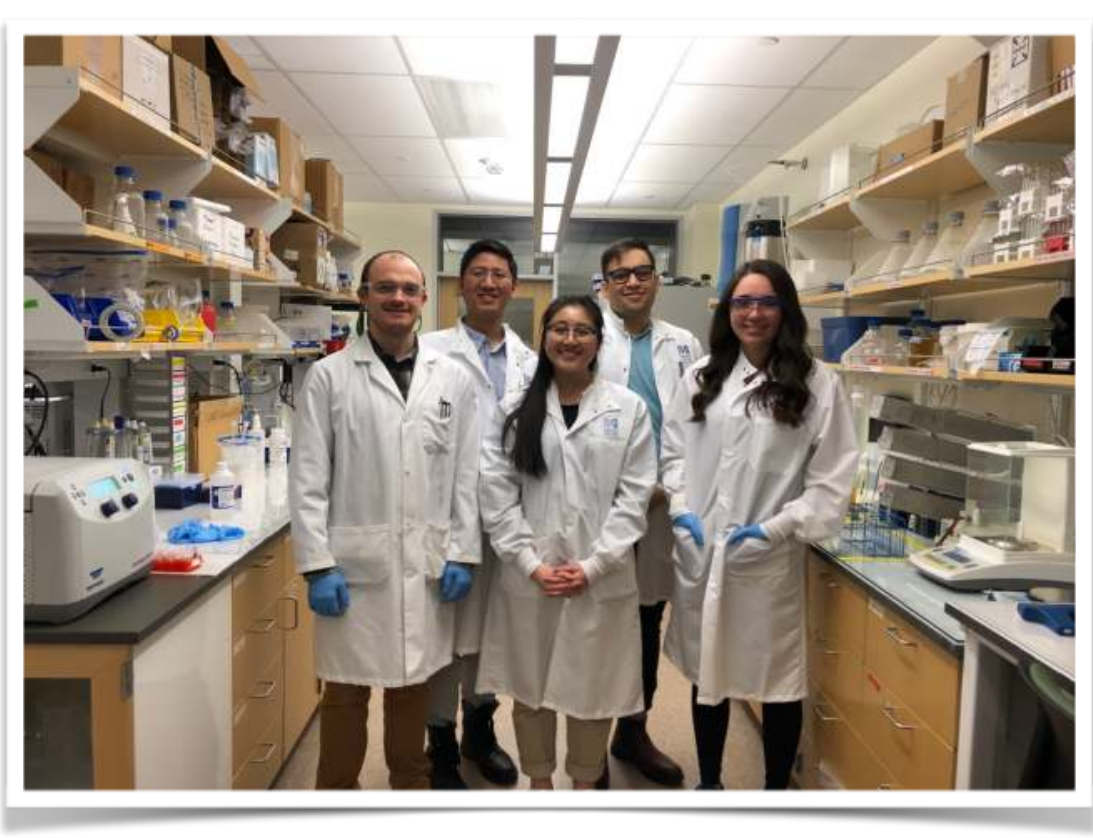

The Dowling Lab

Andrew Gnann Jeremy Liew

Courtney Truong Reyaz Gonzalez Jess Soule Chris Kim
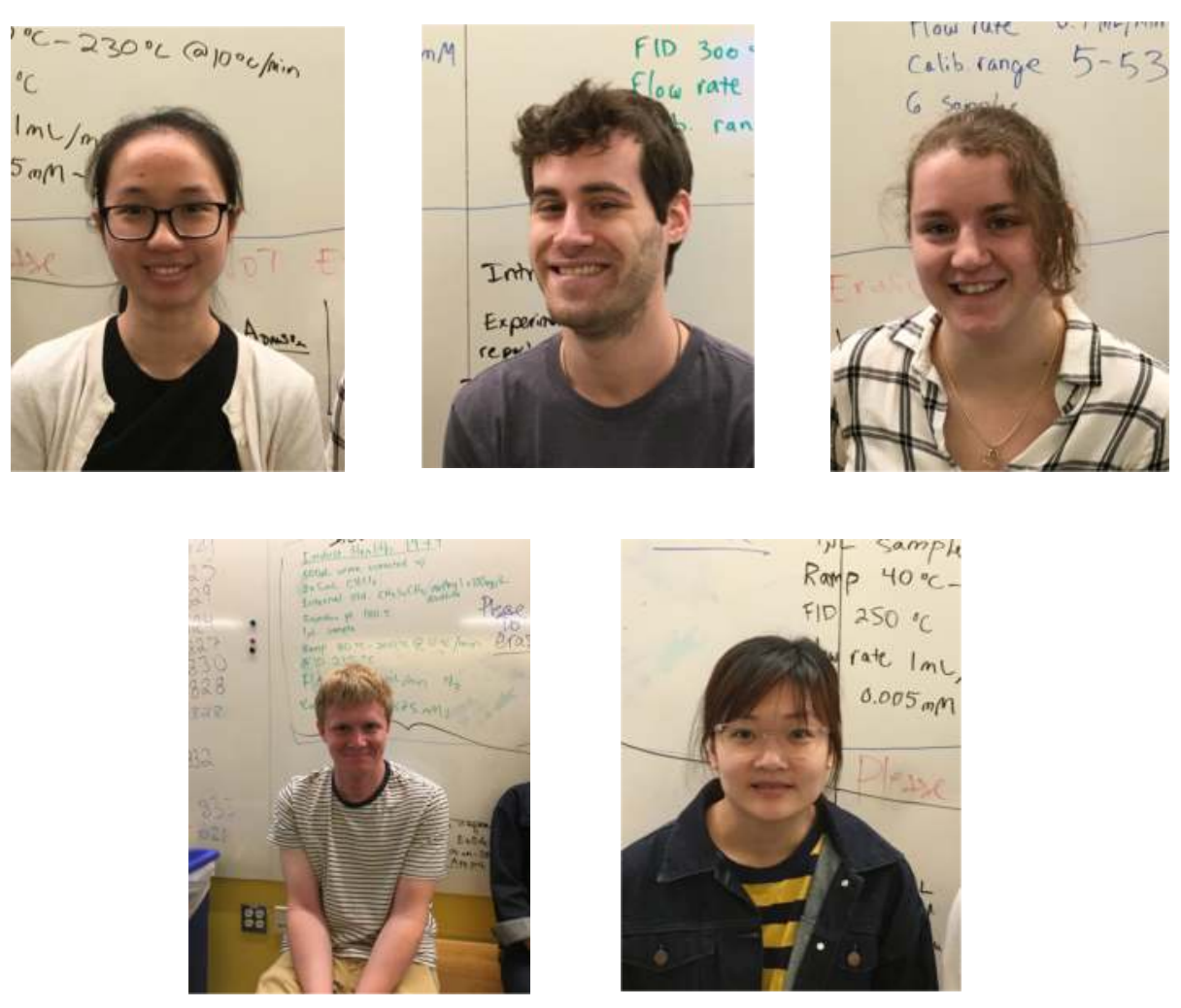

National Science Foundation Funded Summer 2019 Research Assistants (RAs) 
With this award, the Chemistry of Life Processes program is funding Dr. Denyce K. Wicht at Suffolk University and Dr. Daniel P. Dowling at UMass-Boston to research proteins involved in extracting sulfur from naturally occurring organic molecules. The microbial cycling of sulfur-containing substrates is important to understanding how living organisms (including humans) play a role in moving this specific element between earth's water, atmosphere, and terrestrial components. The biochemical interconversions of compounds containing carbon-sulfur bonds and sulfur-oxygen bonds are observed across a range of microorganisms, but the order in which the chemistry proceeds only recently has been discovered. Therefore, these chemical transformations remain largely unexplored. This research entails a collaborative effort by Dr. Wicht and Dr. Dowling to perform fundamental biochemical analyses and obtain structural information for how these biochemical systems function. Research assistants at the undergraduate and graduate level gain experience with enzymology, biochemistry, and protein crystallography. Additionally, participants engage in outreach activities with middle school students and receive specific feedback on lifelong learning skills important to the production of a modern STEM workforce. Strong scientific mentorship provided by PI Wicht and co-PI Dowling contribute to the development of a diverse, globally competitive STEM workforce.

PI Wicht's responsibilities include recruiting, interviewing, and hiring the undergraduate research assistants (RAs), serving as the direct supervisor of the RAs, and managing the experimental results generated at Suffolk University. In March 2019, Wicht and co-PI Dowling identified, interviewed, and hired five undergraduate RAs for full-time employment at Suffolk University for ten summer weeks under the direct supervision of PI Wicht. The five funded RAs (three from Suffolk University and two from UMass-Boston) worked up to 40 hours per week in Suffolk University research laboratories. The main task of the RAs was to produce, purify, and quantify recombinant proteins. 


\title{
National Science Foundation funded summer 2019 research assistants
}

Jonathan Ottinger

University of Massachusetts-Boston

Biology 2020
Son Nguyen

Suffolk University

Biochemistry 2020

\author{
Ngan Phan \\ University of Massachusetts-Boston \\ Biochemistry 2020
}

Kylie McKenna

Suffolk University

Biochemistry 2020

Forensic Science minor
Chaim Wigder Suffolk University

Psychology 2020

Chemistry minor

The application deadline for these positions was March 1, 2019 and the applicant pool was competitive. What did the professional references say about each applicant?

“Jonathan's academic performance is exceptional. He will make a good asset to your lab."
"Ngan is pleasant, polite and has a great attitude. She works very hard to improve her skill set."
"Son is a diligent and detail-oriented student in lab. Her notes are always organized."

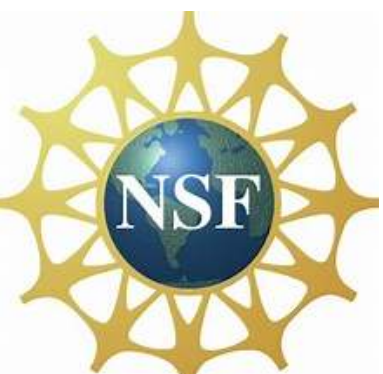

"Kylie shows maturity and a high level of commitment to finishing the job that she started."
"Chaim possesses a strong work ethic and is a great dialogue partner." 


\section{Through a rigorously vetted assessment platform (the Enhancing Learning by Improving}

Process Skills in STEM (ELIPSS) project), the RAs were provided with feedback from assessment experts on the written communication of scientific information pre and post

Assessment Experts: funding period

Meaghan Fallano

Digital Content Developer at Pearson

Adjunct Laboratory Instructor at Suffolk

University

B.S., Chemistry

Ph.D., Chemistry

\section{Nicole Reder}

Program Manager at the Center for

Learning \& Academic Success

Suffolk University

B.S., Chemistry and English Literature

M.A., International Education

\section{Ellane J. Park}

Rollins College

Assistant Professor of Chemistry

B.S., Chemistry

Ph.D. Chemistry

\section{EEIPSS}

\section{Student Name:}

Written Conveying information and understanding to an intended audience through written Communication materials

Rubric Version: WC_prod_Jan10_2017

\begin{tabular}{|c|c|c|c|c|c|c|}
\hline Category & 0 & 1 & 2 & 3 & 4 & 5 \\
\hline $\begin{array}{l}\text { Audience } \\
\text { (Language) }\end{array}$ & & $\begin{array}{l}\text { Ignores intended audience or uses } \\
\text { unsuitable language for the audience }\end{array}$ & & $\begin{array}{l}\text { Considers intended audience, but uses some } \\
\text { unsuitable language for the audience }\end{array}$ & & $\begin{array}{l}\text { Considers audience and uses clear and } \\
\text { suitable language for that audience }\end{array}$ \\
\hline $\begin{array}{l}\text { Audience } \\
\text { (Relevance) }\end{array}$ & & $\begin{array}{l}\text { Poorly conveys the topic's relevance or } \\
\text { importance to the audience }\end{array}$ & & $\begin{array}{l}\text { Adequately conveys the topic's relevance or } \\
\text { importance to the audience }\end{array}$ & & $\begin{array}{l}\text { Effectively conveys the topic's relevance or } \\
\text { importance to the audience }\end{array}$ \\
\hline $\begin{array}{l}\text { Organization/ } \\
\text { Cohesion }\end{array}$ & & Uses disjointed sequence of ideas & & Uses logical sequence of ideas & & Uses logical and effective sequence of ideas \\
\hline $\begin{array}{l}\text { Subject Area } \\
\text { Conventions }\end{array}$ & & $\begin{array}{l}\text { Uses language that is inconsistent with the } \\
\text { norms, formal rules, and informal rules of } \\
\text { the subject area }\end{array}$ & & $\begin{array}{l}\text { Uses language that is somewhat consistent } \\
\text { with the norms, formal rules, and informal } \\
\text { rules of the subject area }\end{array}$ & & $\begin{array}{l}\text { Uses language that is completely consistent } \\
\text { with the norms, formal rules, and informal } \\
\text { rules of the subject area }\end{array}$ \\
\hline $\begin{array}{c}\text { Visual } \\
\text { Representations }\end{array}$ & & $\begin{array}{l}\text { Constructs and uses visual representations } \\
\text { ineffectively and inappropriately }\end{array}$ & & $\begin{array}{l}\text { Constructs and uses visual representations } \\
\text { somewhat effectively }\end{array}$ & & $\begin{array}{l}\text { Constructs and uses visual representations } \\
\text { effectively and appropriately }\end{array}$ \\
\hline $\begin{array}{l}\text { Presentation/ } \\
\text { Formatting }\end{array}$ & & Format and appearance impede readability & & Format and appearance support readability & & Format and appearance enhance readability \\
\hline $\begin{array}{l}\text { Writing } \\
\text { Mechanics }\end{array}$ & & $\begin{array}{l}\text { Uses poor sentence/paragraph structures; } \\
\text { contains many errors in spelling, grammar, } \\
\text { or word usage }\end{array}$ & & $\begin{array}{l}\text { Uses some poor sentence/paragraph } \\
\text { structures; contains some errors in spelling, } \\
\text { grammar, or word usage }\end{array}$ & & $\begin{array}{l}\text { Uses effective sentence/paragraph } \\
\text { structures; contains correct spelling, } \\
\text { grammar, or word usage }\end{array}$ \\
\hline Purpose & & $\begin{array}{l}\text { Does not clearly convey the writing's } \\
\text { purpose }\end{array}$ & & $\begin{array}{l}\text { Clearly conveys the purpose, but the } \\
\text { purpose and content are not well-aligned }\end{array}$ & & $\begin{array}{l}\text { Clearly conveys the purpose, and the } \\
\text { purpose and content are well-aligned }\end{array}$ \\
\hline
\end{tabular}


The five undergraduate RAs hired to work summer 2019 were provided with specific feedback on the lifelong learning skill of written communication, a skill also important to the production of a modern STEM workforce. Specifically, assessment consultants with chemistry expertise applied a vigorously vetted rubric generated via The ELIPSS (Enhancing Learning by Improving Process Skills in STEM) Project (http://www.elipss.com/) to RA writing samples from 300-level undergraduate courses in either analytical chemistry or biochemistry collected during the RA application process. Assessment consultants were compensated for their time and expertise; the compensation was budgeted for in the NSF grant.

In order to serve as an assessment consultant, interested consultants were asked to provide a brief paragraph describing their assessment and/or Chemical Education Research (CER) experience, their interest in participating in this specific project, and their research/teaching interests. Their participation required:

- Reading five writing samples from 300-level undergraduate courses in either analytical chemistry or biochemistry

- Applying the rubric to assess each writing sample. The assessment was accompanied by a written explanation citing specific examples from the writing sample to justify the 0-5 assignment for each category (there are 8 categories). Each written assessment was typed; assessment consultants were instructed to anticipate minimally a one-page word document for each writing sample (reminder, there were five summer RAs 2019)

- Submitting an updated $\mathrm{CV} /$ resume with their completed assessment materials 
Pre-funding assessment data, each category is an average of the data provided from the assessment experts

\begin{tabular}{|c|c|c|c|c|c|}
\hline Category & RA 1 & RA 2 & RA 3 & RA 4 & RA 5 \\
\hline Audience (language) & 5 & 3.75 & 4.75 & 2.5 & 5 \\
\hline Audience (relevance) & 4.25 & 2.5 & 5 & 2.25 & 4.75 \\
\hline Organization/ cohesion & 5 & 3.25 & 4.25 & 2.5 & 4.5 \\
\hline Subject area conventions & 4.5 & 2.75 & 4.75 & 3 & 4.5 \\
\hline Visual representations & 3.75 & 3.25 & 4.25 & 2.75 & 4.75 \\
\hline Presentation / formatting & 4.25 & 3 & 4 & 3 & 4.75 \\
\hline Writing mechanics & 4.25 & 2.25 & 3.75 & 1.5 & 4.25 \\
\hline Purpose & 5 & 3.25 & 4 & 2.75 & 4.5 \\
\hline Overall Average & 4.5 & 3 & 4.3 & 2.5 & 4.6 \\
\hline
\end{tabular}

Slide 6 
In addition to the numerical averages above, each RA received the written feedback from each assessment consultant specific to each category.

The 2019 RAs were provided with assessment data on their written communication skills before they began working summer 2019. Based on these data, the assessment experts hired to consult on this project and co-PI Wicht concluded that two funded RAs would benefit from Suffolk University's Center for Learning and Academic Success (CLAS) services; they were assessed at 2.5 and 3.0, respectively, on a 5.0 scale in "written communication" based on the rubric. Both RAs attended a conversation workshop and a grammar workshop every week (two separate workshops). Importantly, their attendance at CLAS was a compensated activity for both RAs. In other words, the time they spent with CLAS staff was covered by their hourly RA salary as a professional development component of their RA position. In general, the assessment experts and co-PI Wicht agreed that three of the five RAs came into the RA position with fairly high-functioning written communication skills, based on the assessment data; overall, they were assessed at 4.3, 4.5 and 4.6, respectively, on a 5.0 scale. They were given specific feedback on some areas on which to pay particular attention, but were informed that no immediate remediation seemed necessary with respect to the professional development of their written communication. 
RAs received training in protein production, purification, and quantitation, as well as assay development and the collection of rate data

The proposed activities are motivated by specific research questions:

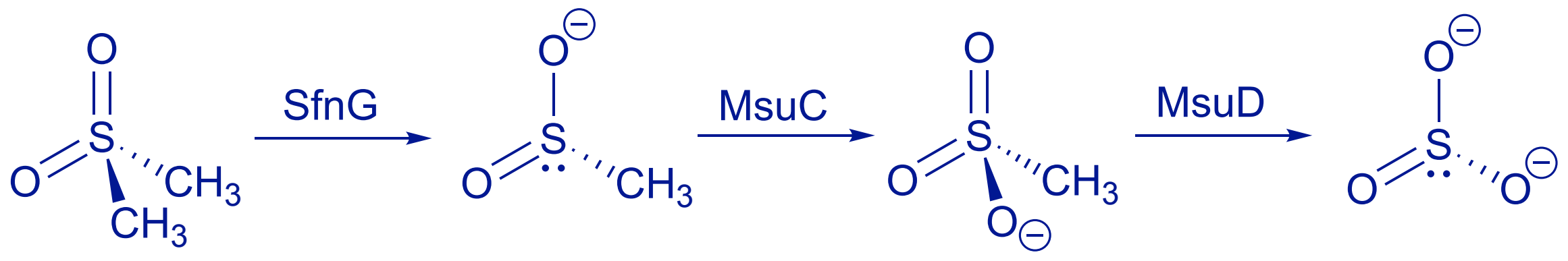

$\mathrm{DMSO}_{2} \quad$ methanesulfinate methanesulfonate sulfite

1) What are the catalytic efficiencies $\left(k_{c a t} / K_{m}\right)$ of the reduced flavin-dependent two component enzymes SfnG, MsuC, and MsuD? Does the reductase component exhibit higher affinity for oxidized flavin relative to the monooxygenases?

2) How broad is the range of $S-\mathrm{CH}_{3}$ containing $\left(C_{1}\right)$ substrates that can be converted to product by SfnG, MsuC, and MsuD?

3) What structural motif(s) do SfnG, MsuC, and MsuD adopt? In crystal structures solved with substrate/product bound, what amino acids map the active site(s)? 


\section{Slide 7 Text:}

The research activities were motivated by specific research questions relevant to three enzymes involved in the conversion of dimethylsulfone to inorganic sulfite.

Importantly, each RA was assigned a unique research goal designed specifically around her/his skill set and was required to produce, purify, and quantify their proteins of interest.

The NSF-funded project provided summer salaries, paid in the form of hourly wages, to the RAs to work in Suffolk University research labs. The RA positions were structured as a job to provide the RAs with lifelong learning skills important to the production of a modern STEM workforce, such as time management and professional accountability.

PI Wicht periodically collected the duplicate pages of the RAs laboratory notebooks to ensure the entries conform to commonly accepted standards for the documentation of scientific data (Kanare, H. M., Writing the Laboratory Notebook, American Chemical Society, Washington, DC, 1985). In addition, RAs were given firm deadlines for ongoing drafts of their final reports and PI Wicht provided detailed feedback to each RA. Importantly, their "writing time" was a compensated activity. In other words, the time they spent writing was covered by their hourly RA salary as a professional development component of their RA position. 
The Function of the

Enzymes SfnG and MsuE

Ngan Phan

University of MassachusettsBoston

Biochemistry 2020

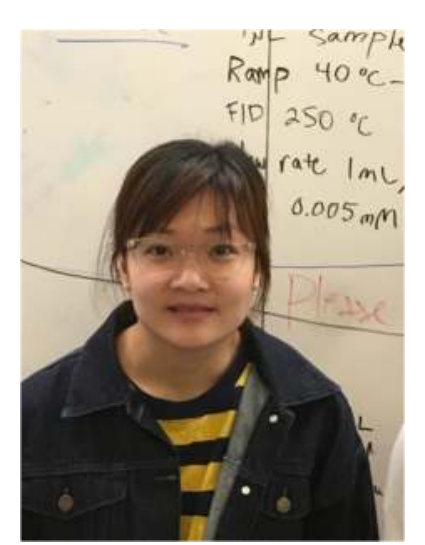

"Ngan is pleasant, polite and has a great attitude. She works very hard to improve her skill set."

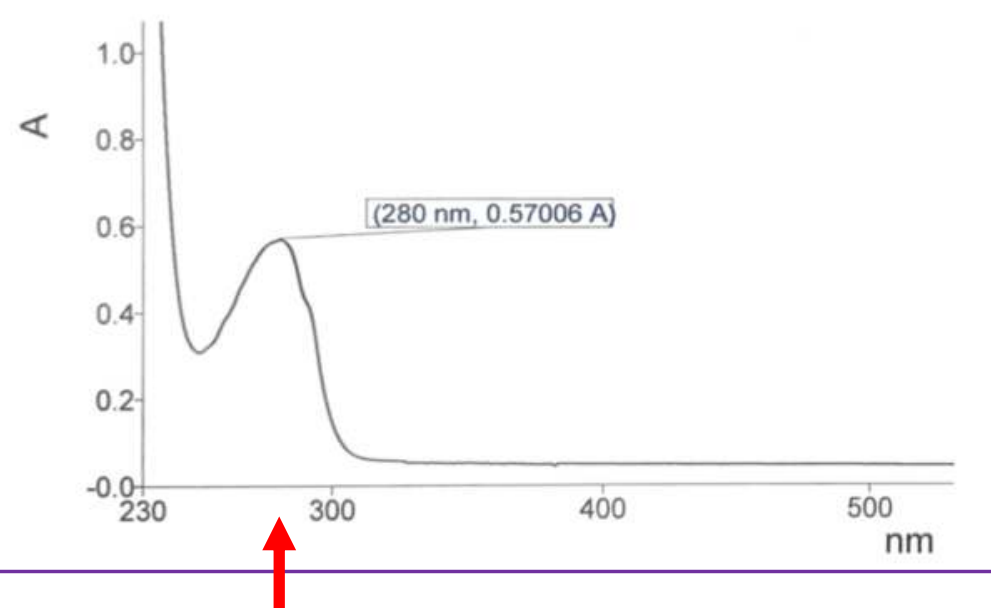

ultraviolet-visible spectroscopy data demonstrating both protein purity and concentration determination via $A_{280 n m}$

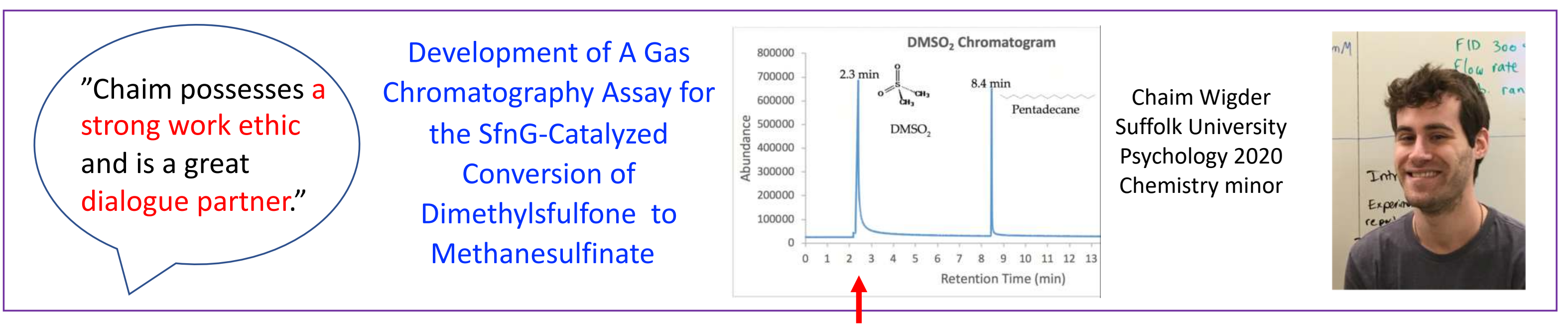

gas chromatography data demonstrating development of a method appropriate for the resolution of substrate from internal standard (mass spec data not shown) 
Fractions from $3^{\text {rd }} \mathrm{MsuC}$ prep

\begin{tabular}{|l|l|l|l|l|l|l|l|}
4 & 5 & 6 & 7 & 8 & 9 & 10 & 11
\end{tabular}

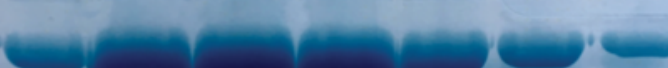

B

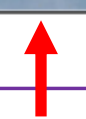

Jonathan Ottinger

University of

Massachusetts-

Boston

Biology 2020

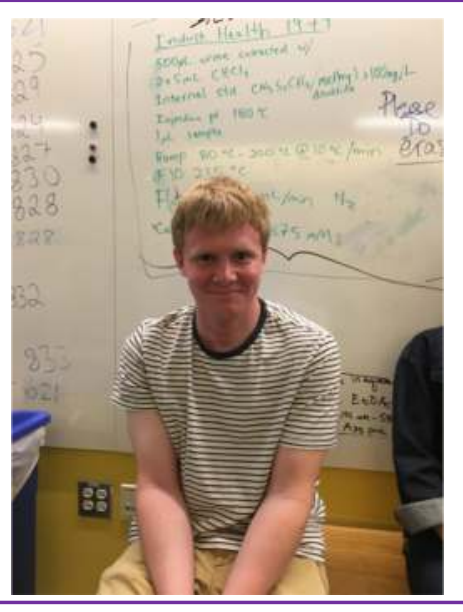

“Jonathan's academic performance is exceptional. He will make a good asset to your lab."
Purification of a Tagged Recombinant form of the monooxygenase

MsuC and Investigation of its Activity on Methanesulfinate

polyacrylamide gel electrophoresis data demonstrating fractions of pure protein consistent with the expected molecular weight

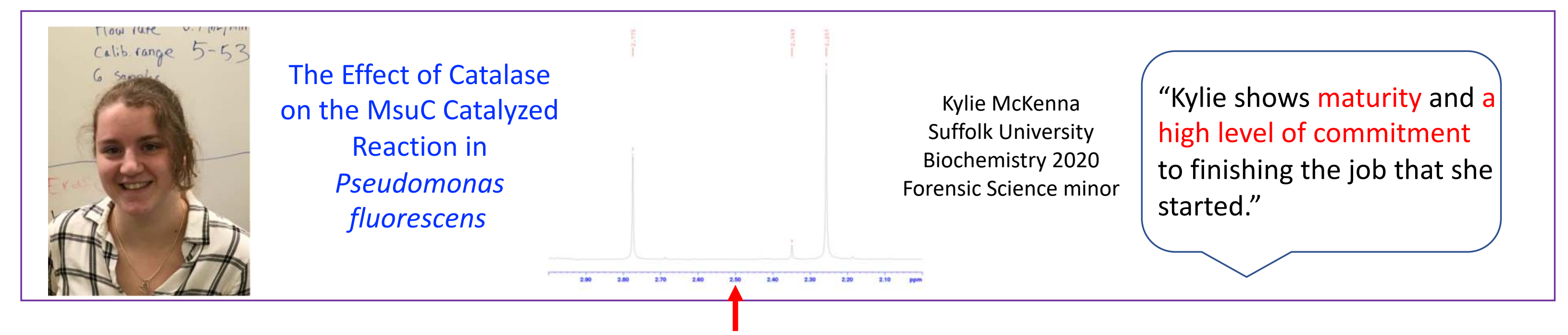

nuclear magnetic resonance spectroscopy data demonstrating conversion of substrate to product 
BSA calibration by Bradford

"Son is a diligent and detail-oriented student in lab. Her notes are always organized."

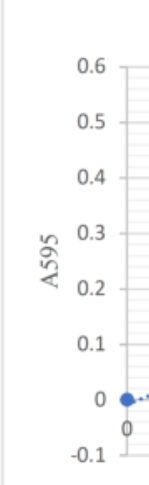

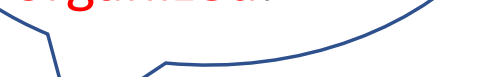

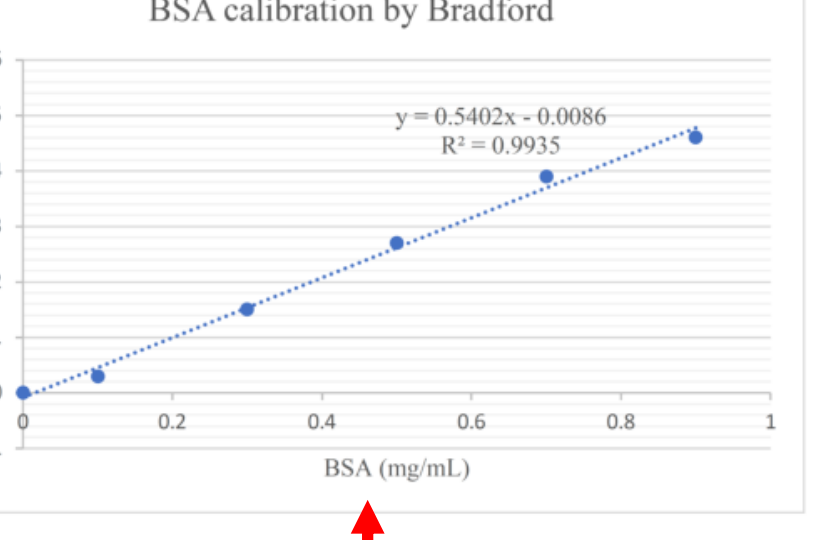

Analysis of conversion from dimethylsulfone to methanesulfinate by flavin-dependent monooxygenase MsuD
Son Nguyen Suffolk University Biochemistry 2020

visible spectroscopy data vs. bovine serum albumin

concentration; a standard curve used for concentration determination of purified proteins

Wicht and Dowling scheduled a group meeting on August 2nd, 2019 to facilitate co-mentorship activities among the funded undergraduate RAs, the funded UMass-Boston graduate students, and all other Dowling research group members. As a requirement of the position, each RA was expected to prepare and deliver a final research presentation at this group meeting and submit a final written research report.

Total Wages Earned by

RAs Summer 2019

$\$ 28,068$
Total Hours Worked by

RAs Summer 2019

1,920

On average, each RA earned $\sim \$ 5,600$ and worked $\sim 40$ hours/week for almost ten weeks 
Pre-funding assessment data compared to post-funding assessment (4 RAs)

\begin{tabular}{|c|c|c|c|c|c|c|c|c|}
\hline Category & $\begin{array}{l}\text { RA } 1 \\
\text { pre }\end{array}$ & $\begin{array}{l}\text { RA } 1 \\
\text { post }\end{array}$ & $\begin{array}{l}\text { RA } 2 \\
\text { pre }\end{array}$ & $\begin{array}{l}\text { RA 2 } \\
\text { post }\end{array}$ & $\begin{array}{c}\text { RA } 3 \\
\text { pre }\end{array}$ & $\begin{array}{l}\text { RA } 3 \\
\text { post }\end{array}$ & $\begin{array}{c}\text { RA } 4 \\
\text { pre }\end{array}$ & $\begin{array}{l}\text { RA } 4 \\
\text { post }\end{array}$ \\
\hline Audience (language) & 5 & 4.7 & 3.75 & 4 & 4.75 & 4.3 & 2.5 & 3.7 \\
\hline Audience (relevance) & 4.25 & 5 & 2.5 & 4 & 5 & 4.3 & 2.25 & 3.3 \\
\hline Organization/ cohesion & 5 & 4.7 & 3.25 & 4.3 & 4.25 & 4.7 & 2.5 & 2.7 \\
\hline $\begin{array}{l}\text { Subject area } \\
\text { conventions }\end{array}$ & 4.5 & 5 & 2.75 & 4.3 & 4.75 & 4.7 & 3 & 3 \\
\hline Visual representations & 3.75 & 4.7 & 3.25 & 4 & 4.25 & 5 & 2.75 & 3.3 \\
\hline $\begin{array}{l}\text { Presentation / } \\
\text { formatting }\end{array}$ & 4.25 & 3.7 & 3 & 4.7 & 4 & 4.3 & 3 & 3.7 \\
\hline Writing mechanics & 4.25 & 4.3 & 2.25 & 3.7 & 3.75 & 4 & 1.5 & 2.3 \\
\hline Purpose & 5 & 4.7 & 3.25 & 3.7 & 4 & 4.3 & 2.75 & 2.7 \\
\hline Overall Average & 4.5 & 4.6 & 3 & 4.1 & 4.3 & 4.5 & 2.5 & 3.1 \\
\hline
\end{tabular}


Slide 11 text:

The 2019 RAs were provided with the post assessment data on their written communication skills based on their final report after their summer RA experience but before the start of the fall 2019 semester.

All RAs who submitted a final written report demonstrated improvement overall.

The two RAs who attended a conversation workshop and a grammar workshop every week (two separate workshops) sponsored by Suffolk University's Center for Learning and Academic Success exhibited greater improvement overall. Anecdotally, the RAs communicated that they found the workshops to be helpful as opposed to punitive.

Perhaps the most valuable/useful aspect to the pre and post assessment process for the RAs was the detailed written feedback provided by the assessment experts (data not presented here). 
Recently published manuscript on the structure and function of MsuC

\section{Biochemical and Biophysical Research \\ Communications \\ Volume 522, Issue 1, 29 January 2020, Pages 107-112}

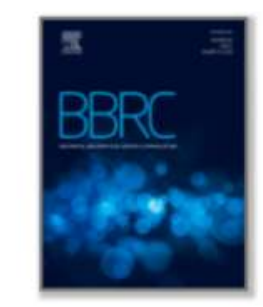

Structure and function of the two-component flavin-dependent methanesulfinate monooxygenase within bacterial sulfur assimilation

Jess Soule ${ }^{a}, 1$, Andrew D. Gnann ${ }^{a}$, Reyaz Gonzalez ${ }^{\text {a }}$, Mackenzie J. Parker ${ }^{\text {b, }}{ }^{2}$, Kylie C. McKenna ${ }^{\text {c }}$, Son V.

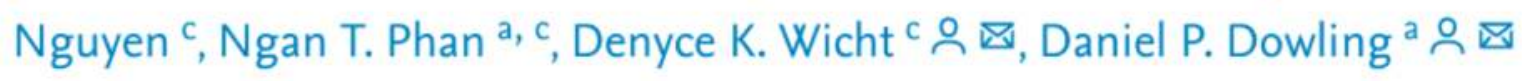

Acknowledgments: NSF for funding (Award 1807480), the assessment consultants who participated in this project, Daniel P. Dowling at UMass-Boston, the Dowling research group members, and all five summer 2019 RAs 